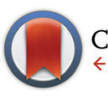

CrossMark \& click for updates

Cite this: Polym. Chem., 2015, 6 , 2726

Received 22nd January 2015, Accepted 16th February 2015

DOI: $10.1039 / c 5 p y 00093 a$

www.rsc.org/polymers

\title{
Surface-initiated $\mathrm{Cu}(0)$ mediated controlled radical polymerization (SI-CuCRP) using a copper plate $\uparrow$
}

\begin{abstract}
Tao Zhang, Yunhao Du, Felix Müller, Ihsan Amin and Rainer Jordan*
Surface engineering with polymer brushes has become one of the most versatile techniques to tailor surface properties of substrates for a broad variety of (bio-) technological applications. We report on a new facile approach to prepare defined and dense polymer brushes on planar substrates by surfaceinitiated $\mathrm{Cu}(\mathrm{O})$ mediated controlled radical polymerization (SI-CUCRP) of numerous vinyl monomers using a copper plate at room temperature. The fabrication of a variety of homo-, block, gradient and patterned polymer brushes as well as polymer brush arrays is demonstrated. The SI-CuCRP was found to be strictly surface-confined, of highly living character, proceeds remarkably fast and results in polymer brushes of very high grafting densities. The brush layer thickness can be modulated by the polymerization time or by the distance of the copper plate to the modified substrate. As the copper plate can be reused multiple times, no additional copper salts are added and only minimal amount of chemicals is needed, the simple and low-cost experimental conditions allows researchers from various fields to prepare tailored polymer brush surfaces for their needs
\end{abstract}

\section{Introduction}

Polymer brushes on solids have emerged as one of the most versatile coatings to introduce chemical functions, control the surface-free energy and friction, modulate bioadhesion, introduce physical and chemical contrasts and to design adaptive interfaces. ${ }^{1-3}$ As a sufficiently high chain grafting density must be achieved to take full advantage of the polymer brush characteristics ${ }^{4}$ surface-initiated polymerization (SIP) of small monomers using a self-assembled monolayer (SAM) as an initiator is advantageous ${ }^{5}$ and allows the preparation of patterned or gradient polymer brushes. ${ }^{6-8}$ Consequently, all polymerization types have been adopted for SIP, but most extensively the surface-initiated atom transfer radical polymerization (SI-ATRP). ${ }^{9,10}$ One of the drawbacks of SI-ATRP was the need of high amount of the toxic and staining copper. However, this could be significantly improved by employing chemical (A(R)GET), electrochemical (eATRP) ${ }^{11}$ or photochemical processes (i.e. PSI-ATRP) $)^{12,13}$ to constantly convert $\mathrm{Cu}^{\text {II }}$ to the instable $\mathrm{Cu}^{\mathrm{I}}$ species in the catalytic cycle. ${ }^{10,14}$ The latest development in SI-ATRP was the sacrificial-anode ATRP (saATRP) by Huck et al. ${ }^{15}$ An interesting alternative to ATRP is the single-electron transfer living radical polymerization (SET-LRP)

Professur für Makromolekulare Chemie, Department Chemie, Technische Universität Dresden, Mommsenstr. 4, 01069 Dresden, Germany.

E-mail: Rainer.Jordan@tu-dresden.de

$\dagger$ Electronic supplementary information (ESI) available: Experimental procedures and characterization data. See DOI: 10.1039/c5py00093a developed by Percec et al. ${ }^{16}$ In contrast to ATRP, the SET-LRP uses only catalytic amounts of nascent $\mathrm{Cu}^{0}$ to generate radicals from organic halides and most importantly, only a ligand but no additional $\mathrm{Cu}$ salts is needed. The SET-LRP is of highly living nature, very fast, yields high molar mass polymers from a broad variety of monomers and proceeds at room temperature. ${ }^{17}$ Recent studies on the mechanism of SET-LRP reported on the absence of radical combination and high end group fidelity. ${ }^{18}$ Subsequently, the "supplemental activator and a reducing agent-ATRP" (SARA-ATRP) has been reported by Matyjaszewski et al. ${ }^{19,20}$ along with a different view on the mechanism of the catalytic cycle. In this article, we will use the descriptive term surface-initiated $\mathrm{Cu}(0)$ mediated controlled radical polymerization (SI-CuCRP) for the here presented polymerization in order to distinguish this polymerization from the various ATRP types that are mediated by added copper halide catalysts. This is to emphasize that in our reaction system the only source of copper is the plate spaced at a macroscopic distance away from the surface-bonded initiator.

While, $\mathrm{Cu}^{0}$ mediated living or controlled radical polymerizations are now frequently used for polymerization in solution, ${ }^{21}$ only two examples demonstrated the versatility of e.g. surface-initiated SET-LRP (SI-SET-LRP) for the preparation of polymer brushes. Walters et l. $^{22}$ prepared poly(amino(meth)acrylate) brushes on silicon substrates with $\mathrm{Cu}^{0}$ powder and found significantly reduced reaction times at low temperatures as compared to SI-ATRP. Huang $e t$ al. ${ }^{23}$ prepared poly(2-hydroxyethyl acrylate) polymer carpets ${ }^{24}$ from functionalized graphene using a copper wire as the catalyst. This improved the 
polymer dispersity ${ }^{25,26}$ and had a beneficial impact on the polymerization kinetics. $^{27}$

For the preparation of polymer brushes on planar substrates, the dimensionality of the solid macroscopic copper catalyst should actually be matched to the dimension of the substrate. Thus, using a copper plate facing the substrate at a given distance is the logical step. Moreover, the copper plate can be used as a lid to confine the reaction space and run the SI-CuCRP in small volumes with and with minimal amounts of chemicals.

Here we report on SI-CuCRP using a copper plate to prepare polymer brushes on planar substrates from a broad variety of vinyl monomers at room temperature. The brush growth rate that was found to be the highest reported to date for surfaceinitiated controlled radical polymerization. To demonstrate the versatility of this approach, we also show the facile preparation of block copolymer brushes, patterned brushes, brush gradients and brush arrays prepared in confined reaction volumes.

\section{Results and discussion}

\section{Surface-initiated $\mathrm{Cu}(0)$ mediated controlled radical polymerization catalyzed by a copper plate (SI-CuCRP)}

Fig. 1a outlines the reaction scheme of SI-CuCRP and shows the simple experimental setup used throughout the experiments. A planar silicon wafer piece covered with a selfassembled monolayer of a standard ATRP-initiator (surfacebound 2-bromoisobutyryl bromide, APTES-BiBB) ${ }^{13}$ were sandwiched with a copper plate and immerged in a solution containing only the monomer and the ligand $\left(N, N, N^{\prime}, N^{\prime \prime}, N^{\prime \prime}-\right.$ pentamethyldiethylenetriamine, PMDETA). Please note that no additional copper salts were added. Alternatively, a drop of the reaction solution sufficient to completely fill the gap between the two plates was applied and the clamped plates remained in a horizontal position during the polymerization (Fig. 1c). The setup was left at room temperature and after indicated time intervals, the plates were separated, the substrate thoroughly cleaned and analyzed. For MMA as the monomer, PMDETA as the ligand in the solvent DMSO, the SI-CuCRP reaction gives a homogenous PMMA brush layer with a dry thickness of $80 \mathrm{~nm}$ after $1 \mathrm{~h}$ reaction time, an rms of $1.58 \mathrm{~nm}$ and a static water contact angle of $\theta_{\mathrm{S}}^{\text {water }}=74 \pm 2^{\circ}$ with agrees well with reported values. ${ }^{28}$ XPS analysis unambiguously confirmed the formation of a PMMA layer (Fig. S1 $\dagger$ ).

Fig. 1b displays the development of the polymer brush thickness with the reaction time. The SI-CuCRP proceeds with an essentially constant brush growth rate of $\delta d=80 \mathrm{~nm} \mathrm{~h}^{-1}$ within the first $1.5 \mathrm{~h}$ and levels around $120 \mathrm{~nm}$. This is by far, the highest brush growth rate for MMA observed to date by any controlled radical polymerization technique at room temperature. For example, Kim et al. ${ }^{29}$ reported $\delta d=3 \mathrm{~nm} \mathrm{~h}^{-1}$ and Huck et $a l^{28} \delta d=15 \mathrm{~nm} \mathrm{~h}^{-1}$ for SI-ATRP of MMA in accelerating aqueous media. One explanation for the high brush growth rate might be loss of polymerization control due to the

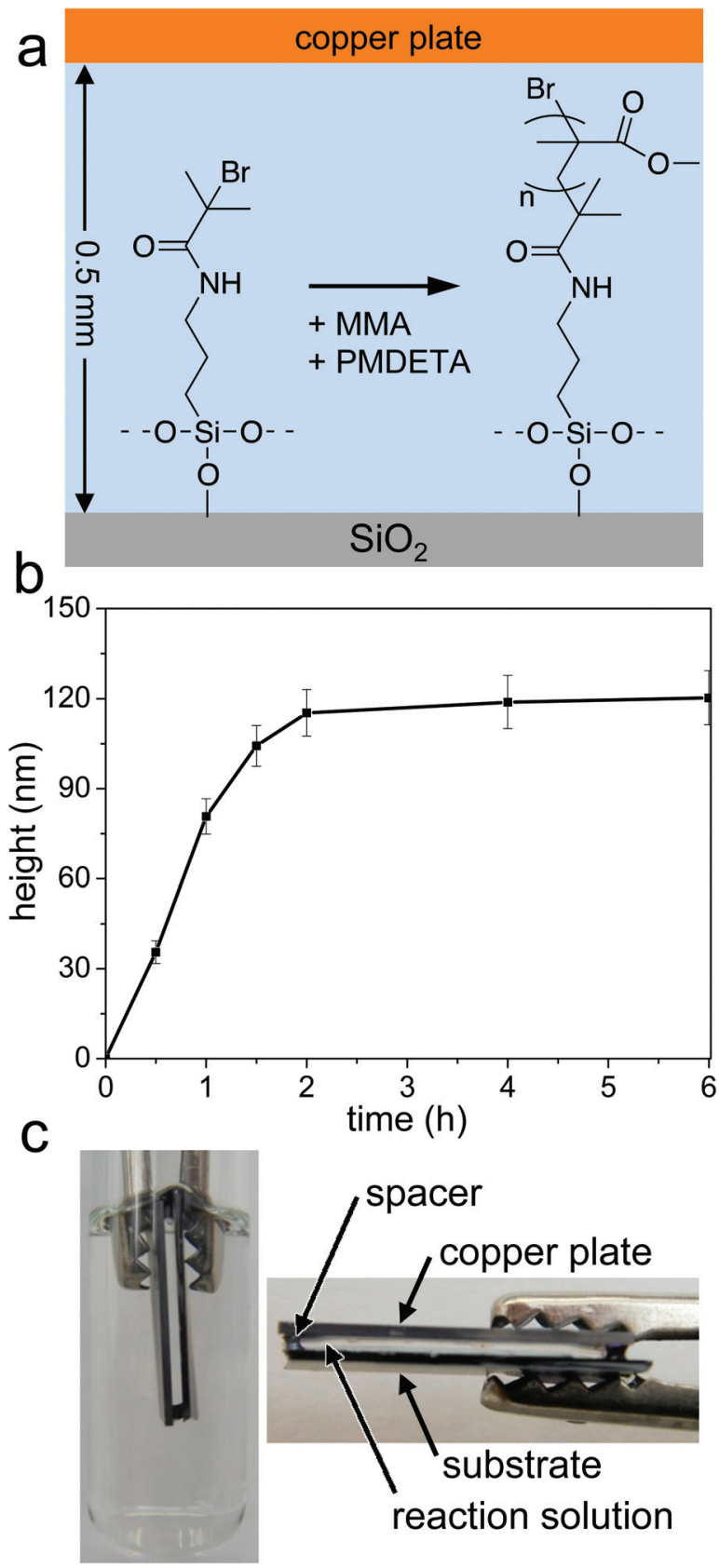

Fig. 1 SI-CuCRP catalyzed by a copper plate. (a) Reaction scheme for SI-CUCRP. An initiator-SAM (APTES-BIBB) on silicon dioxide was sandwiched with a planar copper plate at a distance of $D=0.5 \mathrm{~mm}$. The reaction solution was prepared from $1 \mathrm{~mL} M M A$ and $18.4 \mu \mathrm{L}$ PMDETA without addition of $\mathrm{Cu}^{1 / 11}$ salts. (b) Development of the PMMA brush thickness with the reaction time. (c) Experimental setup. Substrate and copper plate are clamped and submerged in the reaction solution or alternatively in horizontal position with a thin solution film of the reaction solution filling the gap. Control experiments without clamps showed that the use of a stainless steel clamp had no influence on the SI-CuCRP.

extremely low deactivator concentration of $\mathrm{CuBr} / \mathrm{L}$ or $\mathrm{CuBr}_{2} / \mathrm{L}$ as the APTES-BiBB initiator monolayer is the only source of a halogen. In fact, this has been reported for SI-ATRP ${ }^{30}$ which requires addition of an excess of $\mathrm{CuBr}_{2}$ and/or sacrificial 
initiator to the solution in order to control the surfacepolymerization by a sufficient deactivator concentration. However, $\mathrm{Cu}^{0}$-mediated CRP such as SET-LRP is able to produce ultrahigh molar mass polymers in significantly shorter polymerization times as compared to ATRP using very low amounts of initiators. This was largely attributed to its near-complete suppression of termination reactions by combination or transfer. ${ }^{16,17}$ In fact, despite numerous attempts, we could not isolate any detectable amount of polymer from the supernatant solution by precipitation and closer analysis of solution by gel permeation chromatography (GPC) only gave an elution peak for the monomer but no traces of formed oligomers or polymers could be detected. From this, we can only conclude that the SI-CuCRP is surface confined and radical transfer reactions from the surface-initiated polymerization into the solution do not occur.

\section{Repetitive use of copper plate and reaction solution}

As the monomer is only consumed for the formation of the polymer brush, the monomer consumption must be low and should allow a repetitive use of the same reaction solution. Moreover, the catalyst reservoir from the plate is infinite and thus also the plate should be reusable multiple times. We performed five successive experiments using the same copper plate and reaction solution. For each new initiator-modified substrate, almost identical PMMA brush layer thicknesses were determined (Fig. 2).

Even after the $5^{\text {th }}$ reaction we could not isolate PMMA from the solution and the solution showed no coloring by $\mathrm{Cu}$ salts as typical for SI-ATRP. UV-vis spectroscopy of the supernatant solution (Fig. 2b) confirmed the optical appearance of the solution as only minor traces of solubilized $\mathrm{Cu}$ could be detected, causing a broad but very weak adsorption from 500-800 nm. In contrast, SET-LRP catalyzed by a copper wire do cause a coloring of the reaction solution by copper salts as reported by Percec et $a l^{18}$ and in own experiments as described below, probably because of the constant stirring to maintain a sufficient concentration of $\mathrm{Cu}^{0 / \mathrm{I}}$ in the proximity of the surface. With the copper plate directly facing the substrate and no agitation, the diffusion of activating and deactivating copper species in the confined volume is apparently sufficient to maintain the (SI-)CuCRP catalytic circle. The significant reduction of the copper load of the reaction solution is of relevance for the preparation of polymer brushes to be used in a biomedical context.

We also investigated the influence of the oxidation of the copper plate upon its catalytic activity to get first insights on the identity of the main activator $\left(\mathrm{Cu}^{0}\right.$ and/or $\left.\mathrm{Cu}^{\mathrm{I}}\right)$. Freshly cleaned copper plates as well as plates exposed to oxygen plasma for various times were used in identical SI-CuCRP experiments. All plates were able to efficiently catalyze the SI-CuCRP beyond reported brush growth rates for SI-ATRP. However, a stronger oxidation of the plate resulted in a noticeable reduction of its catalytic activity (Fig. S2 $\dagger$ ). Interestingly, we also observed that immediately after the SI-CuCRP the oxidized copper plate surfaces that were in contact with the reaction solution, appeared as if freshly etched/reduced to $\mathrm{Cu}^{0}$, indicating a conversion of the copper oxide layer to elemental copper or the deposition of $\mathrm{Cu}^{0}$ as reported by Percec. ${ }^{31}$

\section{Patterned and gradient polymer brushes by SI-CuCRP}

Since, the SI-CuCRP appears to be surface confined and uses a SAM of surface bound initiators, the preparation of patterned polymer brushes is straightforward with patterned initiatorSAMs. As apparent from Fig. 3a-f, patterned PMMA brushes could be readily produced with patterns of various shapes and on various scales. For all cases, PMMA brush formation only occurred on initiator-covered surface areas. After $1.5 \mathrm{~h}$ reaction time, the dry PMMA brush thickness was found to be $110 \mathrm{~nm}$ which is in agreement with our SI-CuCRP experiments for homogeneous brush preparation (Fig. 1b).

To alter the surface properties continuously, brush gradients are ideally suited. Recently, Huck and Zhou demonstrated the use of a metal plate facing an initiator-functionalized planar substrate to control the brush height on a macroscopic scale. The plates were used either as a working electrode in eATRP $^{11}$ or as a sacrificial anode in saATRP. ${ }^{15}$ In both cases brush gradients were created and the brush height decreased linear with the distance to the facing metal. For SI-CuCRP the copper plate spacing should also influence the height of a
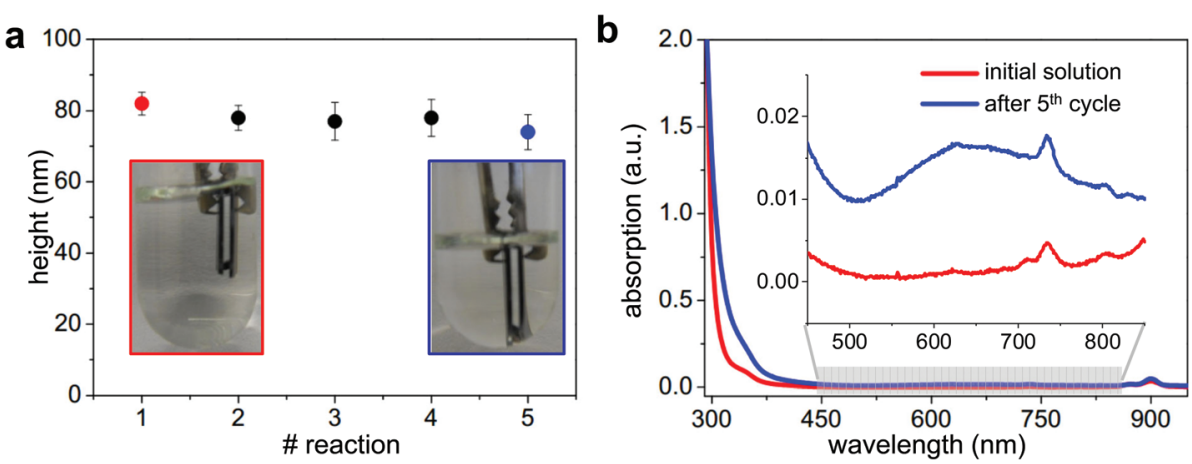

Fig. 2 Reuse of the reaction solution and the copper plate. SI-CuCRP (1 h, r.t., $2 \mathrm{~mL}$ MMA, $36.8 \mu \mathrm{L}$ PMDETA in $1 \mathrm{~mL}$ DMSO, D = 0.5 mm). (a) PMMA brush layer thickness for five consecutive experiments. Insets show clear reaction solution after $1^{\text {st }}$ and $5^{\text {th }}$ reaction. (b) UV/vis spectra of initial reaction solution (red) and after $5^{\text {th }}$ reaction (blue). 

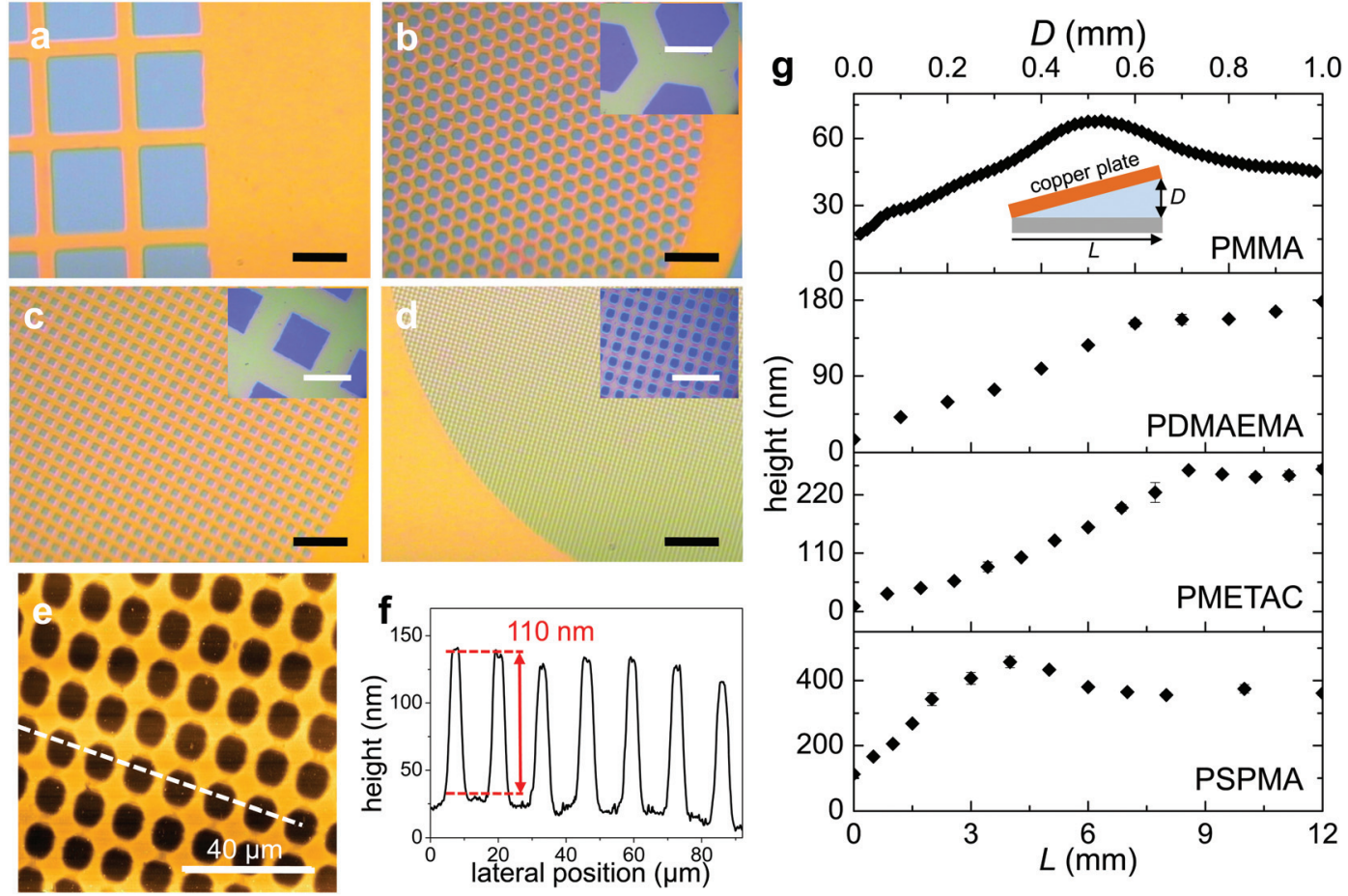

Fig. 3 (a)-(d) Optical micrographs and magnifications (insets) of patterned PMMA brushes with scale bars of $300 \mu \mathrm{m}$ (black) and $40 \mu \mathrm{m}$ (white). The SI-CuCRP of MMA was carried out for $1.5 \mathrm{~h}$ at r.t. (e) AFM scan ( $\mathrm{z}: 160 \mathrm{~nm}$ ) and (f) height analysis along the indicated line in (e). (g) Macroscopic polymer brush gradients prepared from MMA, DMAEMA, METAC and SPMA with a tilted copper plate for $1 \mathrm{~h}$ at r.t.

brush formed at the opposite substrate location as the copper plate is the only of the transition metal. Analog to the experiments described above, SI-CuCRP was performed with a tilted copper plate (plate-substrate distance, $D$, from 0 to $1 \mathrm{~mm}$ over a length of $12 \mathrm{~mm})$. Fig. $3 \mathrm{~g}$ gives the brush thickness development as a function of $D$ for MMA in DMSO (for other monomers in $\mathrm{MeOH}$-water). As apparent from the plots, in all cases, $D$ had a strong influence on the brush height and macroscopic brush gradients were obtained. Interestingly, for SI-CuCRP the brush thickness increases roughly linear with $D$ until a maximum is reached and levels or decrease again. In contrast, for eATRP and saATRP, the brush height scales opposite with the distance to the facing metal plate. This must be accounted to a different reaction mechanism of SI-ATRP and SI-CuCRP or identity of the main activator which is discussed below. ${ }^{18,20}$ The different dependency of the brush height as a function of $D$ for the various monomers is somewhat expectable because of the different polymerization rate for each monomer as well as the different polarity of the reaction solutions because of the different polar monomers. Remarkable is the formation of a $457 \mathrm{~nm}$ thick PSPMA brush at room temperature within $1 \mathrm{~h}$ at $D=0.33 \mathrm{~mm}$.

\section{SI-CuCRP with various monomers}

To demonstrate the general applicability of SI-CuCRP, the reaction was studied for a broad variety of monomers including styrenics, methacrylates, acrylamides and charged monomers. In contrast to the procedure described above, a $\mathrm{MeOH}-$ water mixture was used as the solvent for water soluble monomers and to further accelerate the polymerization (Table 1).

The SI-CuCRP readily converted all monomers to polymer brushes at surprisingly high brush growth rates. As apparent from Table 1, the polymerization is further accelerated in

Table 1 Polymer brush layer thicknesses obtained by SI-CuCRP with various monomers. Hydrophobic monomers were polymerized in DMSO, all others in a $\mathrm{MeOH}$-water $(0.5 \mathrm{~mL}: 1 \mathrm{~mL})$ for $1 \mathrm{~h}$ at room temperature at $D=0.5 \mathrm{~mm}$

\begin{tabular}{llcl}
\hline Monomer $^{a}$ & Solvent & $\delta d^{b}\left(\mathrm{~nm} \mathrm{~h}^{-1}\right)$ & $\theta_{\mathrm{s}}^{\text {water } c}\left({ }^{\circ}\right)$ \\
\hline S & DMSO & 31 & $89 \pm 2$ \\
4 VP & DMSO & 56 & $62 \pm 6$ \\
MMA & DMSO & 80 & $74 \pm 2$ \\
$t$ BuMA & DMSO & 85 & $92 \pm 5$ \\
HEMA & MeOH- $\mathrm{H}_{2} \mathrm{O}$ & 140 & $65 \pm 4$ \\
DMAEMA & $\mathrm{MeOH}-\mathrm{H}_{2} \mathrm{O}$ & 200 & $83 \pm 3$ \\
NIPAM & $\mathrm{MeOH}-\mathrm{H}_{2} \mathrm{O}$ & 190 & $65 \pm 4$ \\
METAC & $\mathrm{MeOH}-\mathrm{H}_{2} \mathrm{O}$ & 180 & $10 \pm 1$ \\
SPMA & $\mathrm{MeOH}-\mathrm{H}_{2} \mathrm{O}$ & 270 & $10 \pm 2$ \\
OEGMA & $\mathrm{MeOH}-\mathrm{H}_{2} \mathrm{O}$ & 106 & $44 \pm 2$ \\
IPOx & $\mathrm{MeOH}-\mathrm{H}_{2} \mathrm{O}$ & 40 & $75 \pm 1$
\end{tabular}

${ }^{a}$ S: styrene, 4VP: 4-vinylpyridine, MMA: methyl methacrylate, $t$ BuMA: tert-butyl methacrylate, HEMA: 2-hydroxyethyl methacrylate, DMAEMA: 2-(dimethylamino)ethyl methacrylate, NIPAM: $N$-isopropylacrylamide, METAC: methacryloxyethyltrimethylammonium chloride, SPMA: 3-sulfopropyl methacrylate potassium salt, OEGMA: oligo(ethylene glycol) methyl ether methacrylate, IPOx: 2-isopropenyl-2-oxazoline. ${ }^{b} \delta d$ : brush growth rate. ${ }^{c} \theta_{\mathrm{s}}^{\text {water }}$ : average static water contact angle from 5 individual measurements on randomly selected locations. 
aqueous environments. Again, we neither see formation of polymer in solution nor a noticeable coloring of the supernatant liquid. Noteworthy is the fast polymerization of the bulky OEGMA macromonomer to a $53 \mathrm{~nm}$ bottle-brush brush within $30 \mathrm{~min}$ which calculates to $\delta d=106 \mathrm{~nm} \mathrm{~h}^{-1}$ that is more than ten folds faster as reported for SI-ATRP $(\delta d=$ $\left.8.75 \mathrm{~nm} \mathrm{~h}^{-1}\right) .{ }^{32}$ In contrast to ATRP, SI-CuCRP was also able to polymerize IPOx. To date, IPOx could be polymerized either by free radical, ${ }^{33}$ living anionic ${ }^{33,34}$ or group-transfer polymerization. ${ }^{35}$ Own attempts with various ATRP recipes resulted in only oligomeric products (unpublished). The accessibility of structurally defined PIPOx by the (SI-)CuCRP poses an interesting alternative and opens a facile route to defined molecular brushes based on poly(2-oxazoline)s.

To investigate the effect of the dimensionality/shape of the bulk copper catalyst, we performed SI-CuCRP with a copper plate and a wire that was wrapped around the magnetic stir bar at the bottom of the reaction vial as for SET-LRP. Furthermore, SI-ATRP were performed using the same initiator, solvent, monomers, temperature and reaction time for direct comparison (Fig. 4). For all monomer types the SI-CuCRP catalyzed by a copper plate is by far the fastest surface-initiated polymerization. Matching the shape of the copper catalyst to the planar substrate not only facilitates the synthetic procedure but also strongly increases the brush growth rate as the comparison to SI-CuCRP or SI-SET-LRP catalyzed by a copper wire demonstrates. Surly, the much larger distance of the wire to the substrate surface can be accounted for the much lower brush thicknesses obtained in this setting. The SI-CuCRP catalyzed by the copper plate outperforms the SI-ATRP by nearly one order of magnitude for MMA. Differences are smaller for NIPAM (1.6 fold) and SPMA (3 fold). Noteworthy is the fast conversion of styrenics (4VP, S by 3.5 and 8 fold, respectively) with an initiator tailored for methacrylates.

The fast conversion of vinyl monomers to polymer brushes poses the question if the SI-CuCRP is really a controlled/living polymerization, because the total amount of deactivator $\left(\mathrm{CuBr} / \mathrm{L}\right.$ and $\left.\mathrm{CuBr}_{2} / \mathrm{L}\right)$ is limited by the initiator SAM and thus extremely low. As no coupled controlled radical polymerization reaction in solution was enabled by the addition of sacrificial initiator, analysis of the average molar mass and

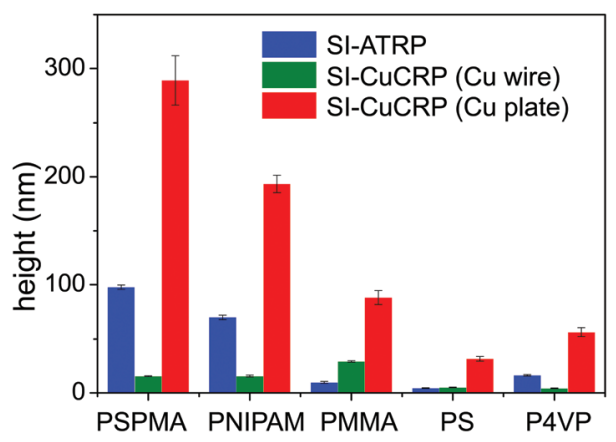

Fig. 4 Comparison of SI-ATRP, SI-CuCRP (SI-SET-LRP) catalyzed by a copper wire and SI-CUCRP using a copper plate for several monomers. dispersity of free polymer and estimation of the grafting density using the brush scaling laws ${ }^{4}$ was not possible. Hence, we prepared a PNIPAM brush on a larger substrate (approx. $4 \mathrm{~cm}^{2}$ ) with a dry thickness of $220 \pm 5 \mathrm{~nm}$ (AFM) and an optical thickness of $230 \pm 8 \mathrm{~nm}$ (ellipsometry). The polymer brush was detached from the substrate by $\mathrm{KOH}$ and analyzed by GPC. The determined number average molar mass was with $M_{\mathrm{n}}=207 \mathrm{~kg} \mathrm{~mol}^{-1}$ very high and the dispersity with $Ð=$ 1.07 very low. This indicates that the SI-CuCRP is not only ultrafast but also highly controlled if not living. For this sample, the PNIPAM brush grafting density, $\sigma$, calculates to 0.81-0.85 chains $\mathrm{nm}^{-2}$ which is, to the best of our knowledge, one of the highest reported grafting densities obtained by any surface-initiated polymerization. In comparison, Zhu et al. ${ }^{36}$ reported a maximum density of 0.61 PNIPAAM chains $\mathrm{nm}^{-2}$ prepared from a dense, preassembled silane-SAM (9.0 initiators $\mathrm{nm}^{-2}$ ) and consecutive SI-ATRP. In a recent and very detailed study, Genzer et al. ${ }^{37}$ investigated degrafted PMMA brushes prepared by SI-ATRP and found typical grafting densities between $0.47-0.58$ chains $\mathrm{nm}^{-2}$.

\section{Block copolymer brushes}

The controlled/living character of SI-CuCRP is further evidenced by the successful preparation of block copolymer brushes. Exploiting the reported high end group fidelity of $\mathrm{Cu}^{0}$ mediated CRP, ${ }^{18}$ we prepared block copolymer brushes by consecutive SI-CuCRP of OEGMA 475 and SPMA with HEMA (Fig. 5). For all experiments homogeneous brush coatings were found. The brush thickness increase by the second PHEMA block was also found to be uniform with a slightly lower increase from the PSPMA to the P(SPMA- $b$-HEMA). Currently, further studies are underway to elucidate the limits of SI-CuCRP to prepare functional multiblocks and repetitive brush extension experiments as in solution, this or similar polymerization types proofed to be feasible to prepare highorder multiblock copolymers. ${ }^{38,39}$

\section{Polymer brush arrays from microliter volumes}

The experimental setup of two facing plates defining a very small reaction space and the minimal monomer consumption offers the possibility to prepare polymer brushes from tiny amounts of chemicals. Inspired by the experiments from Zhou and Huck, ${ }^{15}$ we prepared a similar simple setup with a PDMS mask ( $D=0.5 \mathrm{~mm})$ forming seven channels that were filled with approx. $20 \mu \mathrm{L}$ reaction solution (Fig. 6). After $1 \mathrm{~h}$, the SI-CuCRP resulted in an array of seven polymer brush areas on one substrate in a single reaction step. While for SaATRP already remarkable thick brush layers are reported, ${ }^{15}$ the SI-CuCRP outperforms saATRP for all investigated monomers (e.g. saATRP gave a $30 \mathrm{~nm}$ thick PMETAC brush, SI-CuCRP a $180 \mathrm{~nm}$ thick brush (6 fold)). Please note that as the SI-CuCRP is not restricted to aqueous reaction media and in this example, polymer brushes from aqueous solution as well as DMSO were synthesized in parallel on the same substrate. 

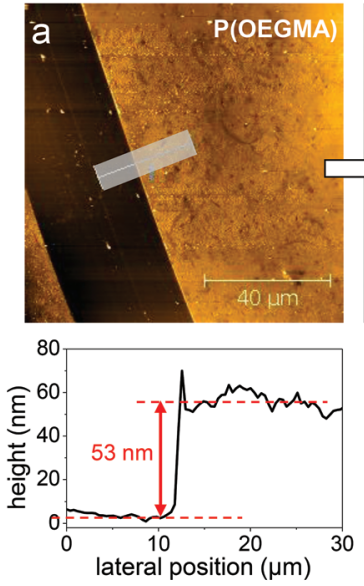
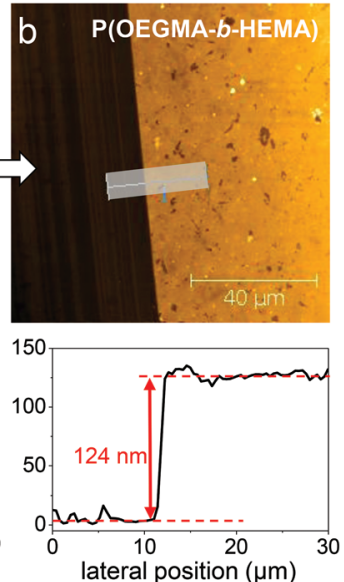
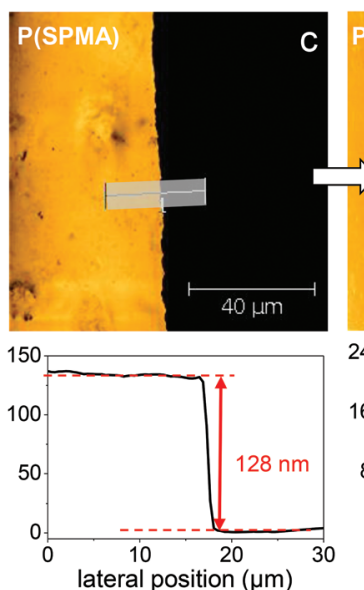
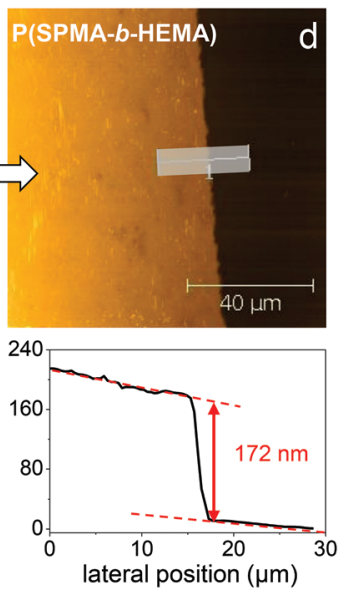

Fig. 5 Preparation of block copolymer brushes by consecutive SI-CuCRP. (a) A P(OEGMA) brush was prepared within 30 min at r.t., cleaned and a scratch defect inflicted into the layer. Layer thickness was evaluated from the area at the rim indicated in grey (upper picture, $x, y: 100 \mu m, z=$ $80 \mathrm{~nm}$ ). Polymer brush thickness is indicated in the respective height analysis shown below. (b) The same sample was subjected to a second SI-CuCRP (30 min) using HEMA to yield P(OEGMA-b-HEMA) of $d=124 \mathrm{~nm}$. (c) Accordingly, a P(SPMA) brush ( $d=128 \mathrm{~nm}$ ) was converted to (d) a P(SPMA- $b$-HEMA) block copolymer brush $(d=172 \mathrm{~nm})$.

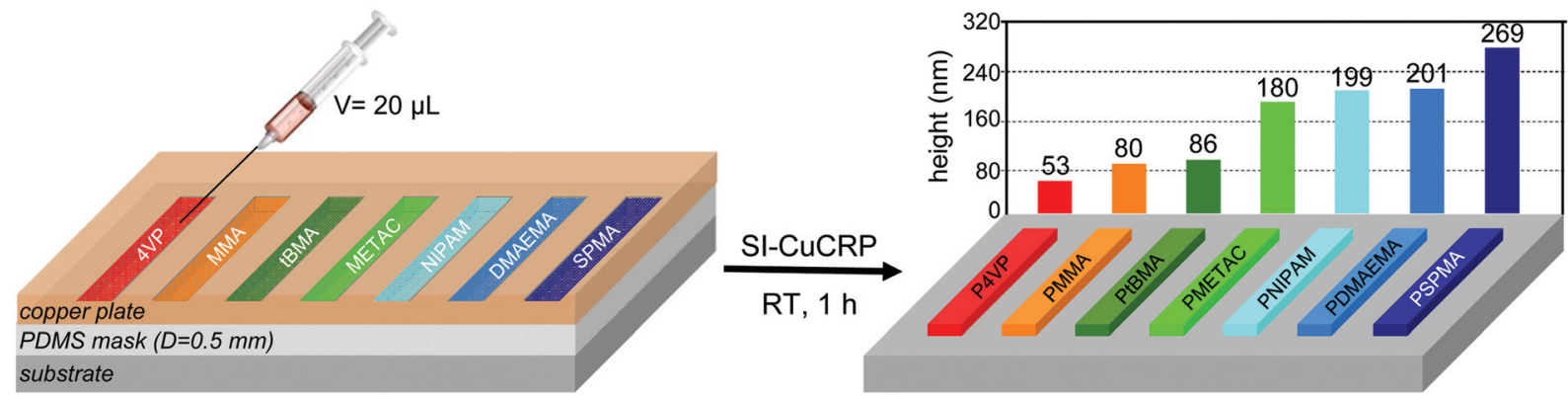

Fig. 6 Fabrication of a polymer brush array by SI-CuCRP using a crosslinked PDMS layer as a mask and spacer $(D=0.5 \mathrm{~mm})$ between the substrate and the copper plate with MMA and IBUMA in DMSO, NIPAM, 4VP DMAEMA, METAC and SPMA in methanol-water. The individual cavities have approx. a $V=20 \mu \mathrm{L}$. Brush thicknesses were evaluated by AFM (average of 3-5 measurements) at the rim of the brush areas defined by the mask.

\section{Considerations on the mechanism of SI-CuCRP}

As shown in Fig. 1a, the initiator for the polymerization is a surface bonded typical ATRP initiator SAM (APTES-BiBB). The solution contains only the solvent (DMSO or water), the vinyl monomer as well as the ligand (PMDETA). The only source of copper is the plate spaced typically $0.5 \mathrm{~mm}$ away from the initiator-SAM. This means, that copper species first have to diffuse over a large distance in order to react with the alkyl halide initiator and start the polymerization. For this, the observed efficiency and speed of the brush formation is very surprising as the copper concentration in the solution is extremely low ${ }^{40}$ although enhanced ${ }^{41}$ by the PMDETA ligand. The observed absences of transfer reactions only partially explain the observed high polymer brush growth rate (Please note, that all SI-CuCRP reactions are carried out at room temperature within 30-60 min). Even more surprising is the observed control or even living character of the SI-CuCRP as evidenced by the formation of block copolymers (Fig. 5) and the very high molar mass and low dispersity as found for the degrafted polymer brushes. At the same time, the obtained grafting density is very high which might indicate that not a bulky copper complex, but a small nascent $\mathrm{Cu}^{0}$ species first reacts with the initiator-SAM and start the SI-CuCRP. The experiments with tilted copper plates (Fig. 3g) show that direct contact of the copper (or copper oxide) with the initiator-SAM is not favorable for the polymerization as brushes are significantly thinner at $D=0$. Larger distances between the bulk copper catalyst and the initiator are also unfavorable as the same experiments show as well as the experiments with a copper wire wrapped around the stir bar at the bottom of the reaction vial (Fig. 4). This might again indicate, that the main activator for SI-CuCRP is produced in the solution and in equilibrium that is dependent on the distance to the solid copper catalyst. In any case, the bulk copper itself can not be the catalyst.

In case Si-CuCRP is following a similar mechanism as described for SET-LRP with nascent $\mathrm{Cu}^{0}$ as the activator its reported extremely high reactivity ${ }^{16}$ could explain our observations. For the initiation of SI-CuCRP following the SET-LRP mechanism, ${ }^{18}$ nascent $\mathrm{Cu}^{0}$ has to react with the APTES-BiBB initiator SAM to $\mathrm{CuBr} / \mathrm{L}$ and initiates the living radical 


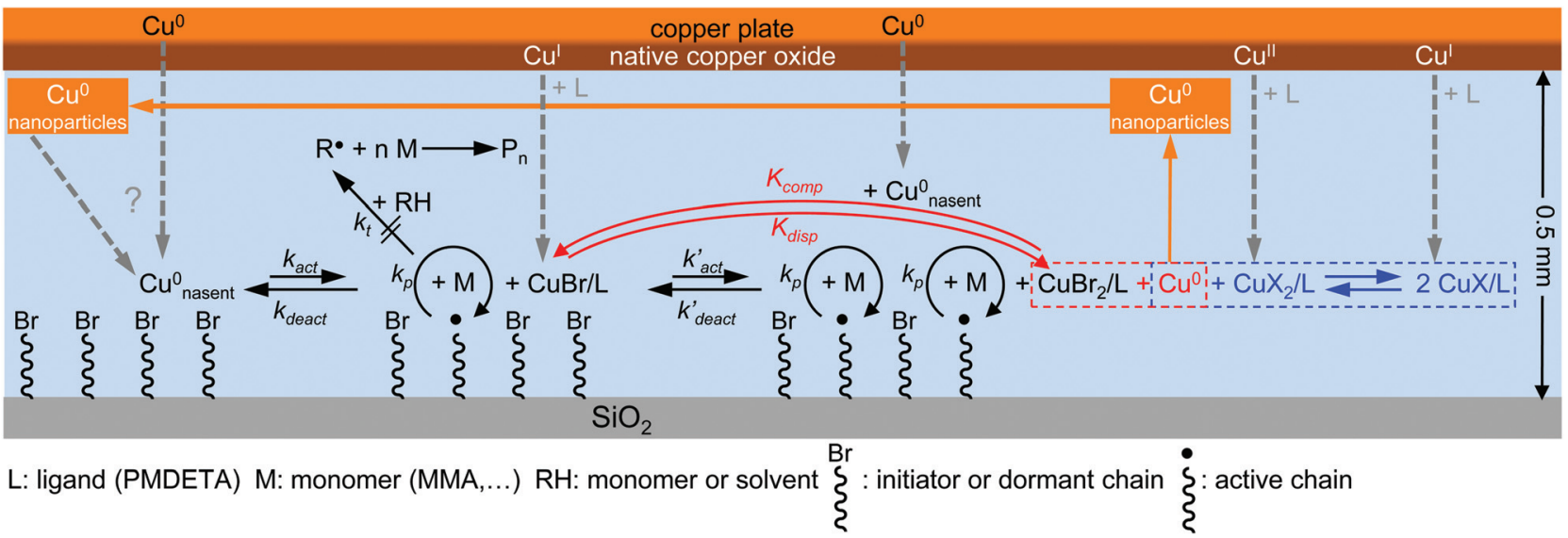

Fig. 7 Preliminary mechanism of SI-CuCRP mediated by a copper plate based on the current mechanisms for the Cu(0)-mediated SARA-ATRP and SET-LRP.

polymerization in equilibrium with $\mathrm{Cu}^{0}$ and a surface tethered P-Br dormant species with $k_{\text {act }} \ll k_{\text {deact }}$ (Fig. 7). At the same time, $\mathrm{CuBr} / \mathrm{L}$ can act as an activator by reaction with an new initiator or dormant $\mathrm{P}-\mathrm{Br}$ to $\mathrm{CuBr}_{2} / \mathrm{L}$ with $k_{\text {act }}^{\prime} \ll k_{\text {deact }}^{\prime}$. Additionally, the unstable $\mathrm{CuBr} / \mathrm{L}$ can disproportionate to $\mathrm{CuBr}_{2} / \mathrm{L}$ and $\mathrm{Cu}^{0}$ (as outlined in red in Fig. 7). ${ }^{42}$ The absence of radical transfer is incorporated in a proposed reaction mechanism. Recently, Percec ${ }^{31}$ investigated the surface of copper wires used for SET-LRP and found evidence for the formation of $\mathrm{Cu}$ nanoparticles and associated changes of the copper wire surface. Indeed, we also see significant changes of areas of the copper plate that were in contact with the solution (experiments with oxidized plates, Fig. S2 $\dagger$ ) as they appear to be freshly reduced right after the SI-CuCRP. This indicate conversion of the copper oxides during the reaction and/or surface reconstruction by re-deposition of elemental copper. ${ }^{31}$ The formation of $\mathrm{Cu}$ nanoparticles is included in our scheme although we have currently no direct evidence of the formation of such particles in SI-CuCRP. Following the SARA-ATRP mechanism, the SI-CuCRP might also start with a $\mathrm{Cu}^{\mathrm{I}} \mathrm{X} / \mathrm{L}$ species as the activator and start the catalytic cycle. They could also participate in an additional redox reaction as proposed in Fig. 7 (blue). On the other hand, our experiments with increasingly oxidized copper plates clearly show that an increase of the copper oxide coating of the plate is not beneficial for SI-CuCRP.

At this point, it is unclear which copper species is the main or sole initial activator in SI-CuCRP and which mechanism is applicable. Currently, we perform experiments to elucidate the reasons for the surprising speed and at the same time high control of SI-CuCRP.

\section{Conclusions}

A new method for surface-initiated polymerization using $\mathrm{Cu}(0)$ mediated controlled radical polymerization (SI-CuCRP) with a copper plate is described. The SI-CuCRP was found to be the fastest surface-initiated controlled/living radical polymerization reported to date and results in very dense polymer brushes. The simple experimental setup and reaction conditions allow the facile synthesis of defined brush layers at room temperature of unparalleled thicknesses within $1 \mathrm{~h}$ at room temperature. The reaction was found to be surface confined and monomers exclusively converted to grafted polymer chains, the reaction volume can be significantly minimized and the reaction solution reused multiple times. Overall minimal amounts of chemicals are needed. The copper load and thus, contamination of the polymer layers was found to be significantly reduced even if compared to a reaction with a copper wire used as the catalyst. The versatility of SI-CuCRP allows the preparation of brushes from a broad variety of monomers in organic solvents and aqueous media. This can also be performed in parallel on the same substrate to prepare polymer brush arrays for high-throughput experimentation. Currently, experiments are ongoing to elucidate the mechanism of the SI-CuCRP and to address the question how the SI-CuCRP is initiated and why it is so fast and efficient.

The fast, facile and very versatile SI-CuCRP mediated by a copper plate should allow researchers from various disciplines to prepare defined polymer brush layers by their own and is therefore expected to have a significant impact on future research and technology related to the tailoring and design of interfaces.

\section{Acknowledgements}

Financial support from the China Scholarship Council (CSC) from the People's Republic of China (PhD grant to T. Z.) is gratefully acknowledged. R.J. and I.A. acknowledges financial support by the Cluster of Excellence "Center for Advancing Electronics Dresden” (cfAED). The authors thank Dr Bernhard Ferse for the measurement of XPS spectra. 


\section{References}

1 M. A. C. Stuart, W. T. S. Huck, J. Genzer, M. Müller, C. Ober, M. Stamm, G. B. Sukhorukov, I. Szleifer, V. V. Tsukruk, M. Urban, F. Winnik, S. Zauscher, I. Luzinov and S. Minko, Nat. Mater., 2010, 9, 101.

2 W. Senaratne, L. Andruzzi and C. K. Ober, Biomacromolecules, 2005, 6, 2427.

3 R. C. Advincula, W. J. Brittain, K. C. Caster and J. Rühe, Polymer brushes, Wiley-VCH, 2004.

4 S. T. Milner, Science, 1991, 251, 905.

5 Surface-Initiated Polymerization I. [In: Adv. Polym. Sci., 2006; 197] (Springer, 2006), pp. 214 pp.

6 J. Genzer and R. R. Bhat, Langmuir, 2008, 24, 2294.

7 U. Schmelmer, R. Jordan, W. Geyer, W. Eck, A. Gölzhäuser, M. Grunze and A. Ulman, Angew. Chem., Int. Ed., 2003, 42, 559.

8 T. Chen, I. Amin and R. Jordan, Chem. Soc. Rev., 2012, 41, 3280.

9 J. Pyun, T. Kowalewski and K. Matyjaszewski, Macromol. Rapid Commun., 2003, 24, 1043.

10 R. Barbey, L. Lavanant, D. Paripovic, N. Schüwer, C. Sugnaux, S. Tugulu and H. A. Klok, Chem. Rev., 2009, 109, 5437.

11 B. Li, B. Yu, W. T. S. Huck, W. Liu and F. Zhou, J. Am. Chem. Soc., 2013, 135, 1708.

12 J. Yan, B. Li, F. Zhou and W. Liu, ACS Macro Lett., 2013, 2, 592.

13 T. Zhang, T. Chen, I. Amin and R. Jordan, Polym. Chem., 2014, 5, 4790.

14 S. Dadashi-Silab, M. Atilla Tasdelen and Y. Yagci, J. Polym. Sci., Part A: Polym. Chem., 2014, 52, 2878.

15 J. Yan, B. Li, B. Yu, W. T. S. Huck, W. Liu and F. Zhou, Angew. Chem., Int. Ed., 2013, 52, 9125.

16 V. Percec, T. Guliashvili, J. S. Ladislaw, A. Wistrand, A. Stjerndahl, M. J. Sienkowska, M. J. Monteiro and S. Sahoo, J. Am. Chem. Soc., 2006, 128, 14156.

17 B. M. Rosen and V. Percec, Chem. Rev., 2009, 109, 5069.

18 M. E. Levere, N. H. Nguyen and V. Percec, Macromolecules, 2012, 45, 8267.

19 Y. Z. Zhang, Y. Wang, C. H. Peng, M. J. Zhong, W. P. Zhu, D. Konkolewicz and K. Matyjaszewski, Macromolecules, 2012, 45, 78.

20 D. Konkolewicz, P. Krys, J. R. Gois, P. V. Mendonca, M. J. Zhong, Y. Wang, A. Gennaro, A. A. Isse, M. Fantin and K. Matyjaszewski, Macromolecules, 2014, 47, 560.

21 N. Chan, M. F. Cunningham and R. A. Hutchinson, Macromol. Rapid Commun., 2011, 32, 604.
22 S. Ding, J. A. Floyd and K. B. Walters, J. Polym. Sci., Part A: Polym. Chem., 2009, 47, 6552.

23 Z. Liu, S. Zhu, Y. Li, Y. Li, P. Shi, Z. Huang and X. Huang, Polym. Chem., 2015, 6, 311.

24 I. Amin, M. Steenackers, N. Zhang, A. Beyer, X. Zhang, T. Pirzer, T. Hugel, R. Jordan and A. Gölzhäuser, Small, 2010, 6, 1623.

25 N. H. Nguyen, X. Jiang, S. Fleischmann, B. M. Rosen and V. Percec, J. Polym. Sci., Part A: Polym. Chem., 2009, 47, 5629.

26 N. H. Nguyen, B. M. Rosen, G. Lligadas and V. Percec, Macromolecules, 2009, 42, 2379.

27 G. Lligadas, B. M. Rosen, C. A. Bell, M. J. Monteiro and V. Percec, Macromolecules, 2008, 41, 8365.

28 D. M. Jones and W. T. S. Huck, Adv. Mater., 2001, 13, 1256.

29 J.-B. Kim, M. L. Bruening and G. L. Baker, J. Am. Chem. Soc., 2000, 122, 7616.

30 K. Matyjaszewski, P. J. Miller, N. Shukla, B. Immaraporn, A. Gelman, B. B. Luokala, T. M. Siclovan, G. Kickelbick, T. Vallant, H. Hoffmann and T. Pakula, Macromolecules, 1999, 32, 8716.

31 N. H. Nguyen, H.-J. Sun, M. E. Levere, S. Fleischmann and V. Percec, Polym. Chem., 2013, 4, 1328.

32 A. Hucknall, D.-H. Kim, S. Rangarajan, R. T. Hill, W. M. Reichert and A. Chilkoti, Adv. Mater., 2009, 21, 1968.

33 N. Zhang, S. Huber, A. Schulz, R. Luxenhofer and R. Jordan, Macromolecules, 2009, 42, 2215.

34 D. A. Tomalia, B. P. Thill and M. J. Fazio, Polym. J., 1980, 12, 661 .

35 N. Zhang, S. Salzinger, B. S. Soller and B. Rieger, J. Am. Chem. Soc., 2013, 135, 8810.

36 S. Wang and Y. Zhu, Langmuir, 2009, 25, 13448.

37 R. R. Patil, S. Turgman-Cohen, J. Srogl, J. Genzer and D. J. Kiserow, Langmuir, 2015, 31, DOI: 10.1021/la5044766, in print.

38 A. H. Soeriyadi, C. Boyer, F. Nyström, P. B. Zetterlund and M. R. Whittaker, J. Am. Chem. Soc., 2011, 133, 11128.

39 F. Alsubaie, A. Anastasaki, P. Wilson and D. M. Haddleton, Polym. Chem., 2015, 6, DOI: 10.1039/C4PY01066C, in print.

40 D. A. Palmer and P. Benezeth, Proc. 14th Int. Conference on the Properties of Water and Steam, 2004, 491.

41 J. Stodola, P. Tremaine, V. Binette and L. Trevani, PowerPlant Chem., 2000, 2, 9.

42 S. Samanta, V. Nikolaou, S. Keller, M. Monteiro, D. A. Wilson, D. Haddleton and P. V. Percec, Polym. Chem., 2015, DOI: 10.1039/C4PY01748J, in print. 